\title{
KAJIAN PENGARUH PEMBANGUNAN JALAN TOL SEMARANG - DEMAK TERHADAP KINERJA JALAN RAYA KALIGAWE
}

\author{
Rachmat Mudiyono ${ }^{1}$ \\ Gata Dian Asfari ${ }^{2}$ \\ Program Studi Teknik Sipil, Universitas Islam Sultan Agung, Jl. Raya Kaligawe km.4 Semarang ${ }^{1,2}$ \\ Penulis Korespondensi e-mail: rachmat@unissula.ac.id
}

\begin{abstract}
The increasing movement causes traffic jams. One of the congestion occurred on Jalan Raya Kaligawe, Semarang. Jalan Raya Kaligawe is a road located close to the coast. So that when the sea water experiences high tide, the road will be inundated by tidal floods. This condition results in very high traffic jams every year. To deal with congestion and overcome the problem of sea water flooding, the government plans to build the Semarang - Demak Toll Road. With the existence of this Toll Road, it is hoped that congestion on the Kaligawe Road will be reduced. But the reduction in congestion needs research. So the researchers conducted a study on the effect of the construction of the Semarang - Demak Toll Road on the performance of the Kaligawe Highway. The purpose of this study, among others, is to determine the level of service, prediction of the diversion of traffic loads and predictions of increasing work on Jalan Raya Kaligawe. This study uses three stages in the research method, namely the identification stage, the data collection and processing stage, and the analysis and conclusion stages. The analysis technique used in this research is the formulation of traffic loading around the location due to development, both at the time and post, added with base traffic to get a real loading on the area of influence with the construction of the Semarang - Demak toll road. . The results of this study show that the port Arterial toll road intersection plan, for reasons of smooth operation and optimization of the main section because it is a National access road, is more appropriate to use 2 phases. Judging from the delays that will arise, the arrangement using 2 phases is better and does not cause a lot of delays on National roads.
\end{abstract}

Keywords : Road Service Level, Traffic Load Transfer, Road Performance

\section{ABSTRAK}

Pergerakan yang terus meningkat menimbulkan kemacetan pada jalan. Salah satu kemacetan terjadi pada Jalan Raya Kaligawe, Semarang. Jalan Raya Kaligawe merupakan jalan yang terletak dekat dengan pesisir pantai. Sehingga saat air laut mengalami pasang, jalan akan tergenang oleh banjir pasang surut air laut. Kondisi ini mengakibatkan kemacetan yang sangat tinggi setiap tahunnya. Untuk menangani kemacetan dan menanggulangi permasalahan banjir air laut pemerintah merencanakan pembangun Jalan Tol Semarang Demak. Dengan adanya Jalan Tol tersebut diharapkan agar kemacetan di Ruas Jalan Kaligawe berkurang. Tetapi berkurangnya kemacetan tersebut perlu dilakukan penelitian. Maka peneliti melakukan kajian pengaruh pembangunan Jalan Tol Semarang - Demak terhadap kinerja Jalan Raya Kaligawe. Tujuan penelitian ini antara lain untuk mengetahui tingkat pelayanan, prediksi pengalihan beban lalu lintas dan prediksi peningkatan kerja Jalan Raya Kaligawe. Penelitian ini mengunakan tiga tahapan dalam metode penelitian yaitu tahapan identifikasi, tahapan pengumpulan dan pengolahan data, serta tahapan analisa dan kesimpulan. Teknik analisis yang digunakan dalam penelitian ini adalah formulasi pembebanan lalu - lintas di sekitar lokasi akibat pembangunan, baik pada saat maupun pasca, ditambahkan dengan lalu lintas dasar (base-traffic) untuk mendapatkan pembebanan yang nyata pada daerah pengaruh dengan dibangunnya jalan tol Semarang - Demak. Hasil dari penelitian ini diketahui bahwa rencana simpang tol Arteri Pelabuhan, untuk alasan kelancaran dan optimalisasi ruas utama karena termasuk jalan akses Nasional, maka lebih tepat apabila menggunakan 2 fase. Dilihat dari tundaan yang akan timbul, pengaturan menggunakan 2 fase lebih baik dan tidak menimbulkan tundaan yang banyak di jalan Nasional.

Kata kunci : Tingkat Pelayanan Jalan, Pengalihan Beban Lalu Lintas, Kinerja Jalan 


\section{PENDAHULUAN}

Pergerakan yang terus meningkat menimbulkan kemacetan pada jalan. Hal ini dikarenakan tidak seimbangnya antara pergerakan dengan sarana dan prasarana. Faktor lain yang menyebabkan kemacetan diantara lainnya adalah tinggi kapasitas jalan, tinggi hambatan samping dan kondisi geometrik jalan. Adapun cara menghitung tingkat kemacetan ditentukan dengan beberapa karakteristik diantara lainnya perhitungan arus lalu lintas, volume lalu lintas, kapasitas jalan, derajat kejenuhan, hambatan samping dan tingkat pelayanan jalan (Tri Angga Prakoso R et al., 2016)

Salah satu kemacetan terjadi pada Jalan Raya Kaligawe, Semarang. Jalan Raya Kaligawe merupakan jalan yang terletak dekat dengan pesisir pantai. Sehingga saat air laut mengalami pasang, jalan akan tergenang oleh banjir pasang surut air laut (Santi et al., 2016). Kondisi ini mengakibatkan kemacetan yang sangat tinggi setiap tahunnya. Tidak hanya genangan air saja tetapi genangan air mengakibatkan kerusakan pada jalan sehingga jalan berlubang dan membahayakan pengguna kendaraan dalam berkendara.

Dalam menghitung kemacetan jalan salah satu karakteristik yang diperlukan adalah mengetahui tingkat pelayanan jalan. Adapun pengertian tingkat pelayanan jalan yaitu suatu ukuran yang digunakan untuk mengetahui kualitas suatu ruas jalan tertentu dalam melayani arus lalu lintas yang melayaninya. Dalam kondisi kemacetan Jalan Raya Kaligawe perlu diketahui tingkat pelayanan jalan eksistingnya. Hasil pengamatan visual dilapangan sering terjadinya kemacetan di Jalan Raya Kaligawe pada jam puncak ngengindikasikan bahwa kapasitas jalan tidak bisa menampung volume kendaraan pada satuan waktu tertentu.

Setelah diketahui tingkat pelayanan jalan maka dilakukan perhitungan besarnya prediksi pengalihan beban lalu lintas Jalan Raya Kaligawe setelah Jalan Tol SemarangDemak dioperasikan. Dan kemudian akan di perhitungkan prediksi peningkatan kinerja Jalan Raya Kaligawe setelah Jalan Tol Semarang - Demak dioperasikan (Ravanelli et al., 2018). Selain itu menurut hasil studi tentang dampak pembangunan infrastruktur yang telah dilakukan menunjukkan hasil bahwa kenaikan stok jalan sebesar $1 \%$ akan menaikkan pertumbuhan ekonomi sebesar 8,8 \% (LPEM FE-UI, 2011). 


\section{METODOLOGI}

Penelitian ini akan mengkaji kinerja lalu lintas sekitar lokasi pembangunan untuk beberapa kondisi, antara lain kondisi existing tanpa pembangunan, kondisi existing dengan pembangunan, kondisi dengan pembangunan pada tahun rencana dan kondisi pada tahun rencana setelah dilakukan penanganan (Sumaryoto, 2010).

Di dalam tahapan ini akan dilakukan kompilasi data dan analisis di dalam rangka analisis besaran dan luasan dampak serta penanganan dampak yang dilakukan (Mawardi \& Khayam, 2018). Dalam melakukan analisis transportasi digunakan beberapa model perhitungan tergantung pada ketersediaan data. Pembebanan perjalanan di sekitar lokasi akibat pembangunan, baik pada saat maupun pasca, ditambahkan dengan lalu lintas dasar (base-traffic) untuk mendapatkan pembebanan yang nyata pada daerah pengaruh dengan dibangunnya jalan tol Semarang - Demak (Permenhub, 2015). Empat tahapan pemodelan lalu lintas yang digunakan adalah sebagai berikut:

\subsection{Perkiraan Bangkitan Perjalanan (Trip Generation)}

Tahap awal dari empat tahapan proses pemodelan (modeling) ini adalah bangkitan perjalanan (Trip Generation) yang dalam hal ini sesuai dengan pembangunan Jalan Tol Semarang - Demak. Dengan mengambil asumsi perbandingan dengan pintu tol jalan yang ada, maka dapat ditentukan hubungan matematis yang menggambarkan tingkat tarikan dan bangkitan perjalanan ke lokasi tersebut.

\subsection{Distribusi Perjalanan (Trip Distribution)}

Trip Distribution pada intinya adalah tahapan untuk mendapatkan matriks asal tujuan (Origin-Destination Matrix) yang akan digunakan dalam proses selanjutnya. Dasar distribusi yang digunakan adalah dengan proses skim, yaitu berupa penentuan minimum path jarak tempuh perjalanan proporsional terhadap intensitas tata guna lahan.

\subsection{Pemilihan Moda (Modal Split)}

Dalam melaksanakan tahapan modal split, ada 2 macam konsep pendekatan, yaitu Trip End Model dan Trip Interchange Modal Split Model.

\subsection{Pembebanan Perjalanan (Trip/Traffic Assignment)}

Tahapan terakhir adalah trip / traffic Assignment. Tahapan ini menggunakan Model matematis yang dirumuskan pada MKJI, 1997. Tahapan ini akan menghasilkan indikator 
kinerja lalu lintas yang berupa V/C ratio (Departemen Pekerjaan Umum, 1997).

\subsection{Pengumpulan Data}

\section{Data Primer}

Untuk mendukung data sekunder yang telah diperoleh dan untuk mendapatkan gambaran kondisi lalu lintas eksisting, pengumpulan data primer dilakukan secara langsung pada lokasi untuk memperoleh informasi penting berkaitan dengan kinerja dan kondisi lalu lintas dan jaringan jalan di sekitar lokasi kajian.

Sebelum survei primer, dilakukan persiapan untuk mendayagunakan sumber daya perolehan informasi sekunder bagi kematangan pelaksanaan survei primer. Pada tahap ini segala informasi yang berkaitan dengan masalah lapangan pada wilayah kajian diramu dengan peta-peta serta teori idealisasi sasaran analisis dan diterjemahkan ke dalam bentuk formulir survei, rencana survei, organisasi lapangan, dan peta - peta detail.

Sebagaimana layaknya dalam proses kajian penataan, pengkajian dan analisis data lainnya, prinsip GIGO (Garbage In Garbage Out) juga akan diterapkan dalam kajian ini, dimana ketetapan dan keakuratan data dan informasi yang diperoleh merupakan kunci utama untuk memperoleh hasil analisis dan rekomendasi yang tepat dan akurat. Sebaliknya apabila data dan informasi yang digunakan tidak memenuhi standar kriteria ketepatan dan keakuratan, maka analisis dan rekomendasi yang dihasilkan juga akan berbeda jauh dari ketepatan dan keakuratan (Afifi et al., 2017).

Kekurangan data yang dibutuhkan dari data sekunder yang telah diperoleh, dilakukan pengamatan langsung atau survei di lapangan. Survei yang dilaksanakan untuk mendapatkan data primer yang diinginkan antara lain :

a) Survei Tarikan - Bangkitan Perjalanan Obyek Pembanding;

b) Survei Inventarisasi Jalan dan Persimpangan;

c) Survei Pencacahan Lalu Lintas di Ruas;

d) Survei Pencacahan Kendaraan di Persimpangan;

e) Survei Kecepatan Sesaat di Depan Lokasi Pembangunan;

\section{Data Sekunder}

Data sekunder diperlukan untuk melengkapi data primer yang sudah diperoleh. Data tersebut diperoleh dari berbagai instansi terkait, seperti Dinas Perhubungan setempat, Badan 
Pusat Statistik serta pihak Pembangun Jalan Tol. Metode yang disusun oleh konsultan dimulai dengan tahap pengumpulan data (data sekunder). Data yang dikumpulkan berupa identifikasi terhadap 2 (dua) masalah pokok yaitu (a) jaringan jalan dan tata guna lahan di kawasan pembangunan; dan (b) rancang bangun (masterplan) pembangunan.

Data jaringan jalan dan tata guna lahan yang perlu diketahui mencakup kelas, peruntukan, dan kewenangan jalan serta pengaturan persimpangan di sekitar lokasi pembangunan. Sedangkan data rancang bangun antara lain mencakup lokasi pembangunan, luasan lahan, luasan bangunan dan peruntukannya serta pengaturan akses keluar masuk.

\section{HASIL DAN PEMBAHASAN}

\subsection{Lokasi Penelitian}

Jalan Tol Semarang - Demak yang akan dibangun terbentang sepanjang 27 kilometer menghubungkan daerah Semarang dengan Demak, Jawa Tengah. Jalan tol ini merupakan bagian dari rangkaian Jalan Tol Trans Jawa walaupun dari segi konektivitas belum ada rencana jaringan jalan tol ke arah timur.

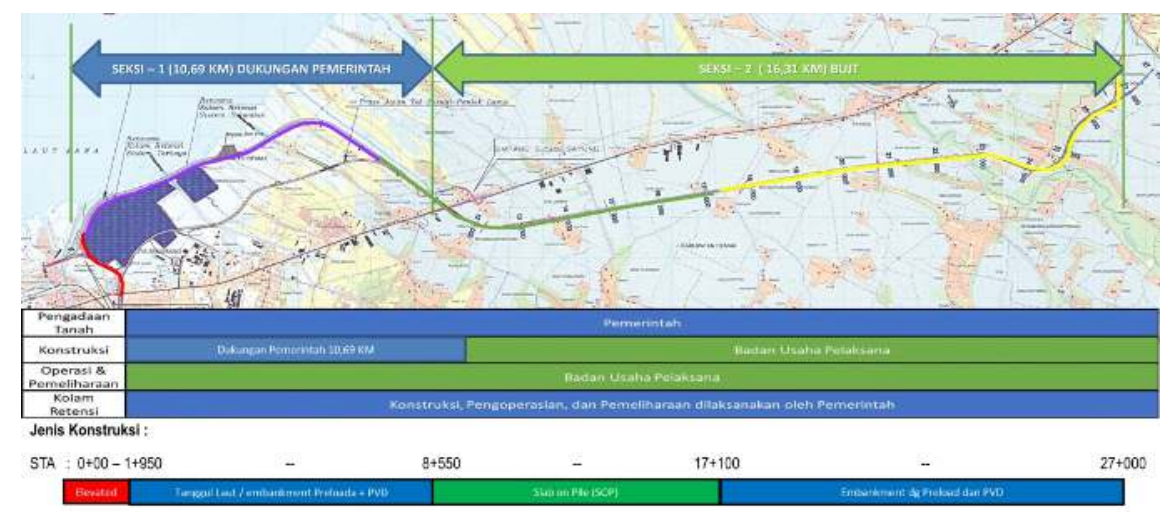

Gambar 1 Pembagian Seksi Tol Semarang - Demak

Sumber : Bahan Tayang Integrasi Tol dan Tanggul Laut DJBM, 2019

Pembangunan jalan tol Semarang - Demak ini terbagi menjadi 2 seksi:

a) Seksi I, Semarang - Sayung (10,69 km)

b) Seksi II, Sayung - Demak (16,31 km)

Ujung barat dari jalan tol ini adalah Jalan Nasional Arteri Pelabuhan sedangkan ujung timur dari jalan tol ini adalah Jalan Arteri Lingkar Demak. Pada jalan tol seksi 1 dan 2 
ini akan dibangun sebanyak 6 jembatan dengan berbagai jenis struktur. Jalan Tol Semarang Demak didesain dengan kecepatan rencana $100 \mathrm{~km} / \mathrm{jam}$, dengan panjang total seksi 1 dan 2 adalah 27 Km, serta memiliki lebar badan jalan 11,7 meter yang terbagi dalam 4 lajur, 2 arah terbagi atau 4/2 D. Dua lajur menuju ke arah Semarang dan dua lajur menuju ke arah Demak, dengan lebar masing-masing per lajur adalah 3,6 meter. Untuk kenyamanan, jalan tol ini juga akan dilengkapi dengan bahu jalan selebar 3 meter di sisi luar jalan dan 1,5 meter di bahu sisi dalam jalan. Jalan tol ini juga dilengkapi dengan median sebagai pembatas jalan di dua arah. Median ini memiliki lebar 1,2 meter.

Untuk kajian dalam analisis dampak pembangunan jalan Tol Semarang - Demak pada penelitian ini fokus di Seksi 1 dan hanya pada pintu Tol Arteri Pelabuhan. Akses Jalan Tol Semarang - Demak Seksi 1 0+000 sampai 10.690 yang berada di wilayah 2 Kabupaten Kota, yaitu Kota Semarang dan Kabupaten Demak, Provinsi Jawa Tengah. Akses jalan tol (Exit Toll) di Kota Semarang berada di Kelurahan Terboyo Kulon, Kecamatan Genuk Kota Semarang, yaitu di Jalan Raya Arteri Pelabuhan.

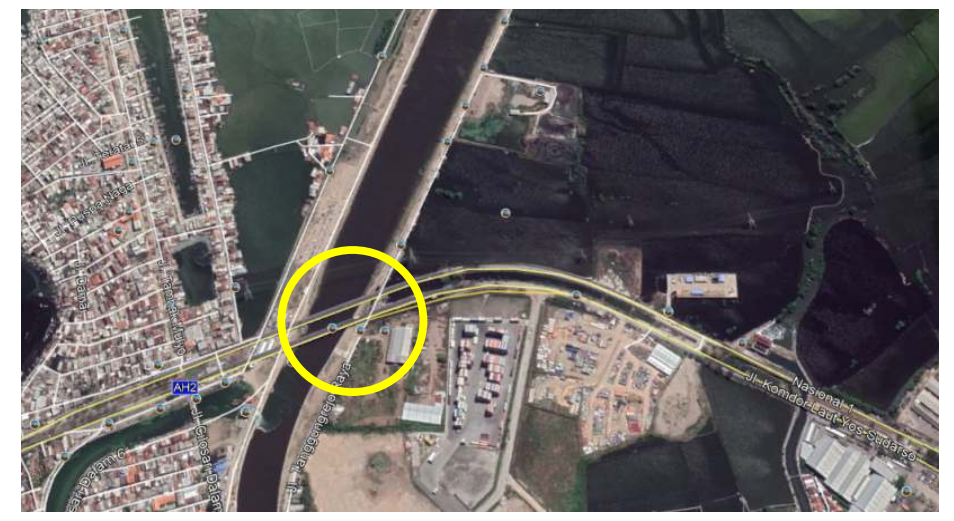

Gambar 2 Lokasi Pintu Tol Arteri Pelabuhan (Semarang) Sumber : Google Earth, 2020

Tabel 1 Volume Lalu Lintas di Jalan Raya Nasional (Semarang)

\begin{tabular}{|c|c|c|c|c|c|c|c|c|c|c|c|c|c|}
\hline \multirow[b]{2}{*}{ Arah } & \multirow{2}{*}{$\begin{array}{c}\text { Tangga } \\
\text { l } \\
\text { Survei }\end{array}$} & \multirow[b]{2}{*}{$\begin{array}{c}\text { Wak } \\
\text { tu }\end{array}$} & \multicolumn{3}{|c|}{ Kendaraan Pribadi } & \multicolumn{2}{|c|}{$\begin{array}{c}\text { Angkutan } \\
\text { Umum }\end{array}$} & \multicolumn{6}{|c|}{ Angkutan Barang } \\
\hline & & & $\begin{array}{l}\text { SP } \\
\text { M }\end{array}$ & $\begin{array}{l}\text { Mobil } \\
\text { Kecil }\end{array}$ & $\begin{array}{c}\text { Mobil } \\
\text { Sedang }\end{array}$ & $\begin{array}{c}\text { Bus } \\
\text { Kecil }\end{array}$ & $\begin{array}{c}\text { Bus } \\
\text { Besar }\end{array}$ & $\begin{array}{l}\text { Pick } \\
\text { Up }\end{array}$ & $\begin{array}{c}\text { Tru } \\
\text { ck } \\
3 / 4\end{array}$ & $\begin{array}{c}\text { Tru } \\
\text { ck } 2 \\
\text { As }\end{array}$ & $\begin{array}{c}\text { Tru } \\
\text { ck } 3 \\
\text { As }\end{array}$ & $\begin{array}{c}\text { Truck } \\
\text { Gand } \\
\text { eng }\end{array}$ & $\begin{array}{l}\text { Juml } \\
\text { ah }\end{array}$ \\
\hline Semar & $2 \mathrm{Mei}$ & Pagi & 82 & 482 & 20 & 27 & 28 & 46 & 321 & 111 & 168 & 184 & 1469 \\
\hline
\end{tabular}




\begin{tabular}{|c|c|c|c|c|c|c|c|c|c|c|c|c|c|}
\hline \multirow{8}{*}{$\begin{array}{l}\text { Arah } \\
\text { ang - } \\
\text { Dema } \\
\text { k }\end{array}$} & \multirow{3}{*}{$\begin{array}{c}\text { Tangga } \\
\text { l } \\
\text { Survei } \\
\\
2020\end{array}$} & \multirow[b]{2}{*}{$\begin{array}{c}\text { Wak } \\
\text { tu }\end{array}$} & \multicolumn{3}{|c|}{ Kendaraan Pribadi } & \multicolumn{2}{|c|}{$\begin{array}{c}\text { Angkutan } \\
\text { Umum }\end{array}$} & \multicolumn{6}{|c|}{ Angkutan Barang } \\
\hline & & & $\begin{array}{l}\text { SP } \\
\text { M }\end{array}$ & $\begin{array}{l}\text { Mobil } \\
\text { Kecil }\end{array}$ & $\begin{array}{l}\text { Mobil } \\
\text { Sedang }\end{array}$ & $\begin{array}{c}\text { Bus } \\
\text { Kecil }\end{array}$ & $\begin{array}{l}\text { Bus } \\
\text { Besar }\end{array}$ & $\begin{array}{l}\text { Pick } \\
\text { Up }\end{array}$ & $\begin{array}{c}\text { Tru } \\
\mathrm{ck} \\
3 / 4 \\
\end{array}$ & $\begin{array}{c}\text { Tru } \\
\text { ck } 2 \\
\text { As }\end{array}$ & $\begin{array}{c}\text { Tru } \\
\text { ck } 3 \\
\text { As }\end{array}$ & $\begin{array}{c}\text { Truck } \\
\text { Gand } \\
\text { eng }\end{array}$ & $\begin{array}{c}\text { Juml } \\
\text { ah }\end{array}$ \\
\hline & & Sore & $\begin{array}{r}24 \\
1\end{array}$ & 680 & 53 & 52 & 45 & 81 & 272 & 78 & 82 & 115 & 1699 \\
\hline & \multirow{2}{*}{$\begin{array}{l}3 \mathrm{Mei} \\
2020\end{array}$} & Pagi & $\begin{array}{r}28 \\
2\end{array}$ & 448 & 38 & 54 & 39 & 32 & 143 & 62 & 69 & 74 & 1241 \\
\hline & & Sore & $\begin{array}{r}26 \\
1 \\
\end{array}$ & 463 & 20 & 37 & 41 & 57 & 157 & 36 & 87 & 98 & 1257 \\
\hline & \multirow{2}{*}{$\begin{array}{l}4 \text { Mei } \\
2020\end{array}$} & Pagi & $\begin{array}{r}1 \\
25 \\
2\end{array}$ & 238 & 23 & 62 & 26 & 42 & 90 & 28 & 55 & 92 & 908 \\
\hline & & Sore & $\begin{array}{r}31 \\
2\end{array}$ & 590 & 31 & 31 & 27 & 61 & 117 & 50 & 38 & 74 & 1331 \\
\hline & $\begin{array}{l}\text { Rata- } \\
\text { Rata }\end{array}$ & & $\begin{array}{r}23 \\
8 \\
\end{array}$ & 484 & 31 & 44 & 34 & 53 & 183 & 61 & 83 & 106 & 1318 \\
\hline \multirow{7}{*}{$\begin{array}{c}\text { Dema } \\
\mathrm{k}- \\
\text { Semar } \\
\text { ang }\end{array}$} & \multirow{2}{*}{$\begin{array}{l}2 \mathrm{Mei} \\
2020\end{array}$} & Pagi & 94 & 153 & 50 & 43 & 33 & 80 & 90 & 13 & 19 & 21 & 596 \\
\hline & & Sore & 72 & 277 & 24 & 29 & 32 & 35 & 84 & 32 & 67 & 41 & 693 \\
\hline & \multirow{2}{*}{$\begin{array}{l}3 \mathrm{Mei} \\
2020\end{array}$} & Pagi & 63 & 269 & 11 & 27 & 14 & 54 & 98 & 22 & 44 & 34 & 636 \\
\hline & & Sore & 37 & 543 & 73 & 44 & 17 & 68 & 86 & 77 & 28 & 29 & 1002 \\
\hline & \multirow{2}{*}{$\begin{array}{l}4 \text { Mei } \\
2020\end{array}$} & Pagi & 35 & 360 & 34 & 38 & 25 & 24 & 78 & 60 & 57 & 51 & 762 \\
\hline & & Sore & 58 & 729 & 22 & 17 & 33 & 77 & 161 & 47 & 69 & 34 & 1247 \\
\hline & $\begin{array}{l}\text { Rata- } \\
\text { Rata }\end{array}$ & & 60 & 389 & 36 & 33 & 26 & 56 & 100 & 42 & 47 & 35 & 823 \\
\hline
\end{tabular}

Sumber: hasil analisis, 2020

\subsection{Komposisi Kendaraan}

Komposisi kendaraan yang melalui ruas jalan nasional yang berada di depan rencana pintu tol Arteri Pelabuhan didominasi oleh kendaraan ringan dan sepeda motor. Untuk lebih jelasnya, komposisi kendaraan pada ruas jalan nasional Arteri Pelabuhan dapat dilihat pada gambar berikut. 


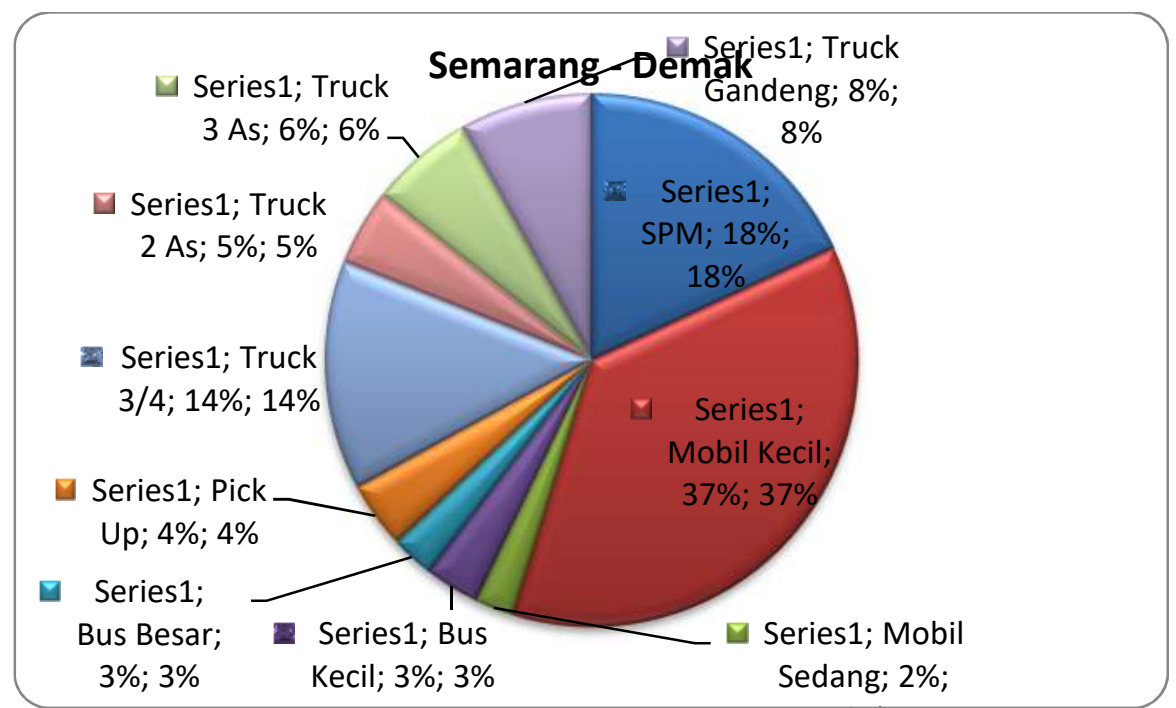

Gambar 3 Komposisi kendaraan di depan pintu tol Arteri Pelabuhan Semarang - Demak Sumber: hasil analisis, 2020

Dari gambar diatas dapat diketahui bahwa kendaraan yang paling banyak melintas di Jalan Nasional arah ke Demak adalah jenis kendaraan pribadi mobil kecil dan sepeda motor dengan prosentase masing - masing sebesar 37\% dan 18\%. Dominasi selanjutnya adalah angkutan barang berupa truck $3 / 4$ sebesar $14 \%$.

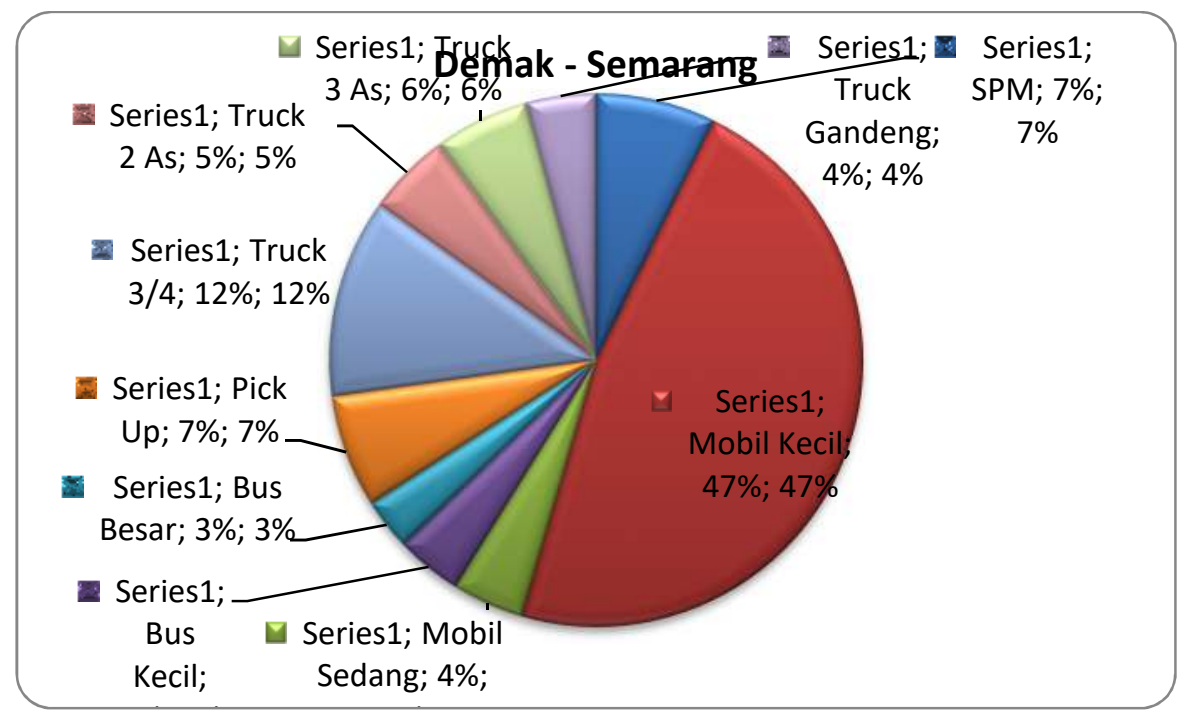

Gambar 4 Komposisi kendaraan di depan pintu tol Arteri Pelabuhan Demak - Semarang Sumber: hasil analisis, 2020

Dari gambar diatas dapat diketahui bahwa kendaraan yang paling banyak melintas di 
Jalan Nasional arah ke Semarang adalah jenis kendaraan pribadi mobil kecil dan truck $3 / 4$ dengan prosentase masing - masing sebesar $47 \%$ dan $12 \%$. Dominasi selanjutnya adalah sepeda motor dan pickup yang memiliki kesamaan prosentase yaitu sebesar $7 \%$.

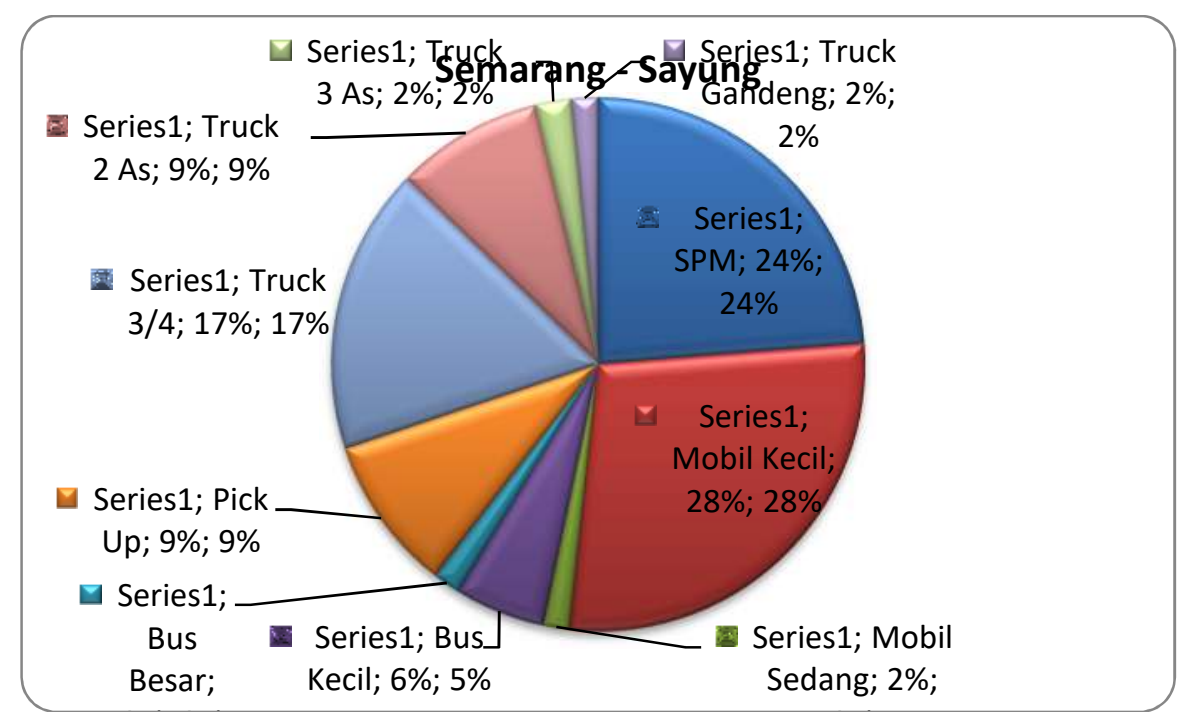

Gambar 3.5 Komposisi kendaraan di depan pintu tol Arteri Pelabuhan Semarang - Sayung Sumber: hasil analisis, 2020

Dari gambar diatas dapat diketahui bahwa kendaraan yang paling banyak melintas di Jalan Nasional arah ke Sayung adalah jenis kendaraan pribadi mobil kecil dan sepeda motor dengan prosentase masing - masing sebesar 28\% dan 24\%. Dominasi selanjutnya adalah truck $3 / 4$ yang memiliki prosentase sebesar $17 \%$.

\subsection{Tingkat Pelayanan Ruas Jalan}

Aksesibilitas ruas jalan merupakan suatu gambaran tingkat kemudahan perjalanan dari suatu tempat asal ke tujuan. Kemudahan perjalanan menunjukkan kinerja lalu lintas pada ruas jalan tersebut. $\mathrm{V} / \mathrm{C}$ ratio merupakan perbandingan antara volume kendaraan yang melewati satu titik jalan dibagi dengan kapasitas jalan tersebut, sehingga rasio dari volume dibanding kapasitas dapat diketahui. Dari hasil perhitungan dan pengamatan lapangan, nilai V/C Ratio pada ruas Jalan Nasional Arteri Pelabuhan - Demak untuk masing - masing arah lalu lintas adalah sebagaimana ditunjukkan pada tabel berikut. 
Tabel $2 \mathrm{~V} / \mathrm{C}$ Ratio rata - rata Jalan Nasional

\begin{tabular}{|c|c|c|c|c|c|c|c|}
\hline $\mathrm{CO}$ & $\mathrm{FC}_{\mathrm{Lj}}$ & $\mathrm{FC}_{\mathrm{PA}}$ & $\mathrm{FC}_{\mathrm{HS}}$ & $\mathrm{C}$ & $\mathrm{V}$ & $\mathrm{V} / \mathrm{C}$ & Tingkat Pelayanan \\
\hline Arah ke Semarang \\
\hline 3300 & 1 & 1 & 1 & 3300 & 823 & 0,24 & $\mathrm{~B}$ \\
\hline Arah Demak & 1 & 1 & 1 & 3300 & 1318 & 0,39 & $\mathrm{~B}$ \\
\hline 3300 & 1 & 1 &
\end{tabular}

Sumber : hasil Analisis, 2020

\section{KESIMPULAN DAN SARAN}

\subsection{Kesimpulan}

Setiap pembangunan kegiatan baru tentu akan menimbulkan dampak terhadap manajemen dan rekayasa lalu lintas mulai dari tahap perencanaan sampai dengan lokasi obyek pembangunan tersebut beroperasi. Dengan adanya pembangunan Jalan Tol Semarang - Demak dapat diketahui hasil penelitian sebagai berikut :

* Rencana Simpang Tol Arteri Pelabuhan, untuk alasan kelancaran dan optimalisasi ruas utama karena termasuk jalan akses Nasional, maka lebih tepat apabila menggunakan 2 fase.

4 Dilihat dari tundaan yang akan timbul, pengaturan menggunakan 2 fase lebih baik dan tidak menimbulkan tundaan yang banyak di jalan Nasional.

Apabila dalam kondisi arus lalu lintas di luar hari normal ( hari raya keagamaan, dll) maka simpang dapat diatur dengan petugas dan APILL di aktifkan lampu sinyal warna kuning (flashing)

\subsection{Saran}

Untuk mengantisipasi dampak lalu lintas yang diakibatkan dari pembangunan Jalan Tol Semarang - Demak, perlu dilakukan tindakan manajemen lalu lintas sebagai upaya untuk mengantisipasi ataupun meminimalisir dampak pada saat operasi, antara lain sebagai berikut:

1) Desain Pintu Akses Keluar Masuk

2) Pemasangan rambu larangan parkir/ berhenti di sekitar pintu keluar masuk.

3) Rambu petunjuk masuk kendaraan untuk membedakan antara arus kendaraan yang masuk dan arus kendaraan keluar.

4) Penempatan petugas untuk mengatur sirkulasi lalu lintas di masing-masing pintu, 
khususnya dimana kendaraan besar datang dan keluar.

\section{DAFTAR PUSTAKA}

Afifi, A., Aurum, K. P., Gondoarum, S. S., Jembatan, A. J., Teknik, P., Jalan, T., ... Rakyat, P. (2017). Analisis Kinerja Dan Kerusakan Jalan Di Ruas Jalan Non Tol Selama Perbaikan Jembatan Cisomang, 3(02), 17-24.

Departemen Pekerjaan Umum (1997). Manual Kapasitas Jalan Indonesia. Jakarta: Departemen Pekerjaan Umum.

Sumaryoto. (2010). Dampak Keberadaan Jalan Tol Terhadap Kondisi Fisik, Sosial, dan Ekonomi Lingkungannya, 1 (2), 161-168.

Lembaga Penyelidikan Ekonomi dan Masyarakat Fakultas Ekonomi Universitas Indonesia (LPEM FE-UI), (Januari 2011).

Mawardi, A. F., \& Khayam, S. (2018). Evaluasi Kinerja Lalu Lintas Sekitar Gerbang Tol Sidoarjo, (October 2017).

Menteri Perhubungan Republik Indonesia (2015). Peraturan Menteri Perhubungan Republik Indonesia No 75 Tentang Penyelenggaraan Analisis Dampak Lalu Lintas.

Ravanelli, M. I., \& Adit, I. K. (2018). Analisis Dampak Lalu Lintas akibat Akses Jalan Tol Malang-Pandaan pada Kawasan Karanglo, Kota Malang (Doctoral dissertation, Universitas Brawijaya).

Santi, R. N., \& Sari, N. P. (2016). Analisis kinerja ruas jalan perkotaan di jalan raya kaligawe km. 7 semarang pada lokasi u-turn (Doctoral dissertation, Fakultas Teknik UNISSULA).

Tri Angga Prakoso R, dkk. (2016). Evaluasi Kinerja Lalu Lintas Ruas Jalan PandaanGempol Sebelum dan Sesudah Adanya Jalan Tol. Jurusan Teknik Sipil, Fakultas Teknik, Universitas Brawijaya. 